\title{
Pegfilgrastim-induced fatigue and leukocytosis improved following dose reduction in a young patient with breast cancer: A case report
}

\author{
HARUKO TAKUWA $^{1}$, WAKAKO TSUJI ${ }^{1}$, TOMOYUKI GOTO ${ }^{2}$, TAKASHI OTSUII ${ }^{3}$ and FUMIAKI YOTSUMOTO ${ }^{1}$ \\ Departments of ${ }^{1}$ Breast Surgery, ${ }^{2}$ Medical Oncology and ${ }^{3}$ Pharmacology, \\ Shiga General Hospital, Moriyama, Shiga 524-8524, Japan
}

Received January 29, 2019; Accepted July 8, 2019

DOI: $10.3892 /$ mco.2019.1907

\begin{abstract}
Dose-dense (DD) chemotherapy is a treatment option for patients with high-risk premenopausal breast cancer. Pegfilgrastim may be administered as prophylaxis against the development of febrile neutropenia and enables the continuation of the DD schedule; however, it is associated with adverse effects, including bone and muscle pain and fatigue. We herein describe our experience with pegfilgrastim administration alongside DD chemotherapy in a patient with breast cancer. A 29-year-old female patient was diagnosed with locally advanced breast cancer during lactation. The patient was diagnosed with cT2N1M0, stage IIB triple-negative breast cancer and underwent four cycles of DD chemotherapy with epirubicin plus cyclophosphamide, followed by four cycles of docetaxel (DTX) every 2 weeks preoperatively, with $3.6 \mathrm{mg}$ pegfilgrastim administered subcutaneously on day 3 of each cycle. The absolute neutrophil count (ANC) was $2,700,8,400$, $11,100,13,300$ and $15,000 / \mathrm{mm}^{3}$ on day 1 of each cycle. The patient experienced fatigue after each pegfilgrastim injection and was considered to be a high responder to pegfilgrastim. Therefore, $1.8 \mathrm{mg}$ pegfilgrastim on day 3 of the first DD-DTX cycle was recommended. On day 1 of the second cycle, the ANC was $13,090 / \mathrm{mm}^{3}$. The patient experienced less fatigue after the administration of $1.8 \mathrm{mg}$ pegfilgrastim, but there was a significant decline in her performance status. As there is currently no evidence of pegfilgrastim dose reduction to below $1.8 \mathrm{mg}$, pegfilgrastim was omitted on day 3 . On day 14 , the patient developed viral enteritis, fever $\left(38^{\circ} \mathrm{C}\right)$, and an ANC of $297 / \mathrm{mm}^{3}$. Therefore, the third cycle was postponed. After 1 week, the patient's ANC recovered to $2,480 / \mathrm{mm}^{3}$ and she was administered the third cycle with $3.6 \mathrm{mg}$ pegfilgrastim on day 3. Between January 2015 and March 2018, a total of 55 patients with breast cancer received chemotherapy with
\end{abstract}

Correspondence to: Dr Haruko Takuwa, Department of Breast Surgery, Shiga General Hospital, 5-4-30 Moriyama, Moriyama-shi, Shiga 524-8524, Japan

E-mail: st24057@yahoo.co.jp

Key words: breast cancer, dose-dense chemotherapy, pegfilgrastim-induced fatigue pegfilgrastim at the Shiga General Hospital. No patients other than the one presented herein experienced leukocytosis during chemotherapy. Although this was a rare complication, a dose of $1.8 \mathrm{mg}$ pegfilgrastim was effective in palliating the patient's symptoms and preventing DD chemotherapy discontinuation.

\section{Introduction}

Dose-dense (DD) chemotherapy every 2 weeks is commonly prescribed for patients with high-risk, invasive, operable breast cancer (1-5). The prophylactic use of pegfilgrastim is also recommended by consensus guidelines in order to prevent chemotherapy-induced febrile neutropenia (FN) (1-10). FN is a potentially life-threatening condition characterized by the development of fever in addition to chemotherapy-induced neutropenia. The FN risk may be mitigated by reducing chemotherapy dosage or extending dosing intervals. However, these measures also reduce the relative dose intensity of the chemotherapy and, consequently, survival rates. Therefore, a granulocyte colony-stimulating factor is often administered to manage chemotherapy-associated FN and to allow anticancer drugs to be administered more effectively. Similar efficacy and safety profiles have been observed in individual studies (11-16) comparing an average of 11 days of filgrastim treatment with pegfilgrastim, and a meta-analysis $(17,18)$ suggested that, overall, pegfilgrastim may be more efficacious compared with filgrastim. While daily administration of filgrastim is required, pegfilgrastim is administered as a single once-per-cycle injection. Based on the convenience and patient adherence, pegfilgrastim may be preferred to filgrastim for the prevention of chemotherapy-induced FN. Pegfilgrastim at $3.6 \mathrm{mg}$ is considered safe and effective for Japanese patients with breast cancer and has been administered in the country since September 2014 (19,20). Numerous reports have demonstrated that the prophylactic use of pegfilgrastim is associated with clinical and economic benefits; however, symptomatic adverse events, such as bone and back pain and fatigue, are frequently reported $(19,21,22)$. We herein report the case of a patient with breast cancer who required pegfilgrastim dose reduction to $1.8 \mathrm{mg}$ during DD chemotherapy after experiencing severe fatigue and leukocytosis. Although such complications are rare, pegfilgrastim dose reduction was effective in palliating the symptoms and preventing interruption of DD chemotherapy. Since pegfilgrastim at $3.6 \mathrm{mg}$ was first approved in Japan, 
55 patients with breast cancer who received chemotherapy at Shiga General Hospital were administered this agent between January 2015 and March 2018, The medical records of all 55 patients were retrospectively reviewed, and the laboratory data of this patient were compared with those of the 54 other patients with breast cancer receiving chemotherapy along with pegfilgrastim.

\section{Case report}

A 29-year-old woman presented to the outpatient clinic of the Department of Breast Surgery at Shiga General Hospital (Moriyama, Japan) during lactation with a lump in her right breast. Physical examination revealed a mass $\geq 2 \mathrm{~cm}$ in size without skin invasion in the upper-lateral region, along with axillary lymph node enlargement.

Ultrasonography, computed tomography and breast magnetic resonance imaging revealed a breast mass and axillary lymph node enlargement on the right side. Core needle biopsy led to the diagnosis of a high-grade invasive ductal carcinoma that was triple-negative [for estrogen receptor (ER), progesterone receptor, and human epidermal growth factor receptor (HER)2]. The Ki-67 labeling index was $80 \%$, basal cytokeratins 5/6 were focally positive, and androgen receptor was negative (Fig. SI). The tumor was radiologically classified as cT2N1M0 stage IIB according to the eighth edition of the Union for International Cancer Control-TNM classification (23).

The patient was premenopausal and had two children, and preservation of fertility was not considered necessary. She was found to be BRCA mutation-negative, and had no history of other diseases. Thus, preoperative chemotherapy was commenced, using four cycles of DD-90 mg/m² epirubicin and $600 \mathrm{mg} / \mathrm{m}^{2}$ cyclophosphamide (EC), followed by four cycles of DD-75 mg/m² docetaxel (DTX) every 2 weeks, along with $3.6 \mathrm{mg}$ of pegfilgrastim administered on day 3 of each cycle (1-5).

Absolute neutrophil count (ANC) was measured at the start of each cycle and was found to increase gradually (Fig. 1A). The patient also experienced significant fatigue after each pegfilgrastim injection, worsening the Eastern Cooperative Oncology Group performance status score (from 0 to 1 ) for 3 days. Expert physicians of the cancer board, comprising breast surgeons, medical oncologists and pharmacologists, concluded that the patient was highly sensitive to pegfilgrastim, and recommended decreasing the dose to $1.8 \mathrm{mg}$ on day 3 of the first DD-DTX cycle. Subsequently, on day 1 of the second DD-DTX cycle, her ANC was reduced slightly to $13,090 / \mathrm{mm}^{3}$. The patient also experienced less fatigue after the pegfilgrastim dose was halved; however, she still experienced a significant decline in performance. Given that no published evidence exists regarding administration of pegfilgrastim at doses $<1.8 \mathrm{mg}$, it was omitted from the second DD-DTX cycle onwards. The patient also wished to switch to filgrastim administration. On day 14 , the patient developed viral enteritis and fever $\left(38^{\circ} \mathrm{C}\right)$, with an ANC of $297 / \mathrm{mm}^{3}$. Therefore, the third cycle of DD-DTX was postponed, and the patient was commenced on oral levofloxacin $(500 \mathrm{mg})$ for 5 days. The patient's ANC had recovered to $2,480 / \mathrm{mm}^{3} 1$ week later, and the third cycle of DD-DTX was initiated, using $3.6 \mathrm{mg}$ of pegfilgrastim on day 3 . The patient still experienced fatigue, albeit milder, due to the absence of continuous pegfilgrastim administration and lack of leukocytosis.

Patients. Since pegfilgrastim $(3.6 \mathrm{mg})$ was first approved in Japan, 55 patients with breast cancer who underwent chemotherapy at Shiga General Hospital were administered this agent between January 2015 and March 2018. The medical records of all 55 patients were retrospectively reviewed.

Chemotherapy is regularly prescribed for relatively young, high-risk patients with breast cancer, including ER-negative patients and those who are ER-positive but exhibit high Ki-67 indices. According to patient data reviewed by our team, 6 of the 55 patients $(10.9 \%)$ had bilateral breast tumors or multiple tumors on one side. One patient had metachronous bilateral breast cancer; however, data regarding previous history of breast cancer were not available. Therefore, 60 tumors from 55 patients were investigated in total (Table SI). Chemotherapy was administered as primary adjuvant therapy in 49 patients $(89.1 \%)$, and for other situations (adjuvant systemic therapy of local recurrence or second-primary ipsilateral breast cancer without distant metastasis) in 6 patients (10.9\%). Furthermore, 3 patients had metachronous bilateral breast cancer with a previous history of chemotherapy on the contralateral side, and 2 patients experienced local recurrence without distant metastasis, both of whom had a previous history of primary therapy. Additionally, a 31-year-old patient with metastatic breast cancer was administered high-dose emergency chemotherapy, owing to the rapid growth of liver metastases.

Patients were administered EC every 2 or 3 weeks, DTX every 2 or 3 weeks, DTX $\left(75 \mathrm{mg} / \mathrm{m}^{2}\right) /$ cyclophosphamide (700 $\mathrm{mg} / \mathrm{m}^{2}$ ) every 3 weeks, or nab-paclitaxel (nab-PTX; $260 \mathrm{mg} / \mathrm{m}^{2}$ ) every 3 weeks $(24,25)$. In patients with HER2-positive breast cancer, a loading dose of $8 \mathrm{mg} / \mathrm{kg}$ trastuzumab followed by a maintenance dose of $6 \mathrm{mg} / \mathrm{kg}$ was used in conjunction with taxane-based therapy (DTX, DTX/cyclophosphamide, or nab-PTX) every 3 weeks. A proportion of patients who received triweekly DTX and were at risk of FN received pegfilgrastim, including those aged $\geq 65$ years and those with locally advanced breast cancer and infectious or ulcerative disease, reduced performance status, history of FN, or neutropenia (8-10). Patients received 4-6 cycles of each regimen along with $3.6 \mathrm{mg}$ of pegfilgrastim on days 2-4 (24-72 $\mathrm{h}$ after administration of chemotherapy).

Supportive treatment for patients receiving the EC regimen consisted of $6.6 \mathrm{mg}$ of dexamethasone and $0.75 \mathrm{mg}$ of palonosetron administered intravenously on day 1, $125 \mathrm{mg}$ aprepitant administered on day 1 and $80 \mathrm{mg}$ on days 2 and 3 (26), and $8 \mathrm{mg}$ dexamethasone administered orally twice daily on days 1-3. For taxane-based regimens, $6.6 \mathrm{mg}$ dexamethasone was administered intravenously on day 1 . Furthermore, each patient was instructed to wear two surgical gloves that were a size too small for their hands to prevent peripheral neuropathy, beginning $30 \mathrm{~min}$ before taxane administration and ending $30 \mathrm{~min}$ after the end of the infusion (27).

The completion rates of scheduled chemotherapy regimens are shown in Table SII. Causes of dose reduction included prolonged neutropenia or anemia related to chemotherapy, mainly occurring in elderly patients and those with 
A
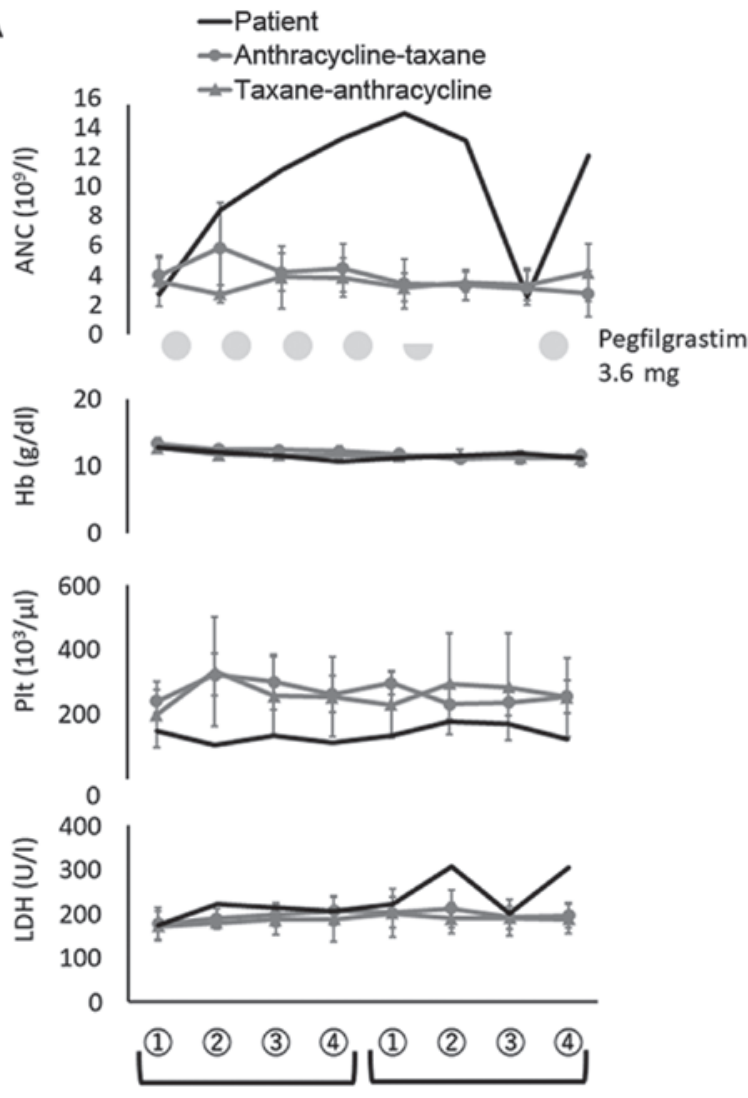

Cycles of chemotherapy

B

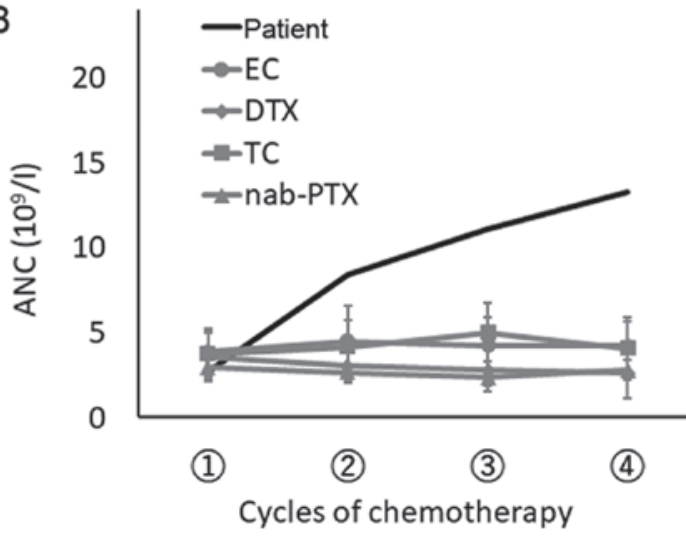

Figure 1. (A) Median ANC, hemoglobin, platelet count and LDH changes in our patient on day 1 of each cycle. The black line shows the ANC changes in this case; the gray line with circle and triangle points shows ANC changes in patients receiving anthracycline followed by a taxane-based regimen, and those who received taxane followed by anthracycline, respectively. Light gray circle and semicircle indicate $3.6 \mathrm{mg}$ and $1.8 \mathrm{mg}$ pegfilgrastim, respectively, for the present case on day 3. (B) Median ANC changes on day 1 of each cycle in each indicated regimen. The black line shows ANC changes in our patient during DD-EC. Gray line with circle, rhombus, square and triangle points indicate ANC changes in other patients who received EC, DTX, TC and nab-PTX, respectively. The EC and DTX groups include patients who underwent DD chemotherapy every 2 weeks. ANC, absolute neutrophil count; Hb, hemoglobin; Plt, platelets; LDH, lactate dehydrogenase; DD, dose-dense; EC, epirubicin $\left(90 \mathrm{mg} / \mathrm{m}^{2}\right)$ and cyclophosphamide $\left(600 \mathrm{mg} / \mathrm{m}^{2}\right)$; DTX, docetaxel $\left(75 \mathrm{mg} / \mathrm{m}^{2}\right)$; TC, docetaxel $\left(75 \mathrm{mg} / \mathrm{m}^{2}\right)$ and cyclophosphamide $\left(700 \mathrm{mg} / \mathrm{m}^{2}\right)$; nab-PTX, nab-paclitaxel $\left(260 \mathrm{mg} / \mathrm{m}^{2}\right)$.

comorbidities. Furthermore, 12 patients underwent sequential anthracycline and taxane treatments with pegfilgrastim in both regimens (Table SIII). The ANC changes in these patients are shown in Fig. 1A, and B shows the ANC changes observed in all patients apart from the subject of this report during each regimen (the subject of this case report is denoted as patient 1 in Table SIII). The median ANC count on day 1 of each cycle was $4,195 / \mathrm{mm}^{3}$ (range, $1,400-9,300 / \mathrm{mm}^{3}$ ) across the 55 patients prior to chemotherapy on day 1 of each cycle. No patients other than the subject of this report developed leukocytosis during chemotherapy.

\section{Discussion}

Pegfilgrastim-induced fatigue is known to occur in $10-20 \%$ of patients $(19,21,22)$, and can interfere with quality of life and treatment adherence. The mechanisms of fatigue secondary to pegfilgrastim are not fully understood; however, they appear to involve bone marrow expansion, hyperstimulated production of novel bone marrow cells, and augmented activity of pre-existing bone marrow owing to the elevation of cytokine levels and induction of leukocytosis (27-29).

Conversely, pegfilgrastim-induced hyperleukocytosis is reported in $<1 \%$ of the patients, but is not always associated with adverse clinical effects (30). Hyperleukocytosis is defined as a peripheral leukocyte count of $>100 \times 10^{3} / \mu 1$. Rheingold and Lange previously reported that hyperleukocytosis may cause death via central nervous system hemorrhage or thrombosis, pulmonary leukostasis and metabolic imbalances, particularly when accompanied by tumor lysis $(31,32)$.

In this report, the proportion of patients who underwent sequential anthracycline and taxane treatments with pegfilgrastim was small. This was due to pegfilgrastim not being administered with regimens such as triweekly DTX or weekly paclitaxel (Table SIII). Pegfilgrastim represents an important supportive therapy for ensuring the continuation of the DD schedule. ANC normally recovers to baseline values (day 1 of administration) if patients receive pegfilgrastim along with chemotherapy $(19,33)$. Kosaka et al reported changes in ANC during the first cycle of chemotherapy for 177 Japanese patients who received $3.6 \mathrm{mg}$ pegfilgrastim on day 2 . ANC increased to a maximum of $11 \times 10^{3} / \mu 1$ on day 11 , and decreased to $<10 \times 10^{3} / \mu 1$ by day 15 (20). As shown in Fig. 1, none of the patients, apart from the subject of this case report, developed leukocytosis during chemotherapy, regardless of the treatment regimen. Furthermore, no major hematological changes were observed in any of these patients. Supportive treatment during chemotherapy was prescribed equally to almost all patients. Other supportive treatments, such as oral dexamethasone, only exerted a minor effect on leukocytosis in our patient. Additionally, the severe fatigue observed in our patient can be distinguished from chemotherapy-induced fatigue by the presence of leukocytosis following pegfilgrastim administration.

The cancer board considered application other granulocyte colony-stimulating factors, such as filgrastim, as alternatives to $3.6 \mathrm{mg}$ pegfilgrastim. Our patient did not receive filgrastim, since it requires daily administration until ANC recovery due to its shorter biological half-life. The patient wanted to reduce her frequency of hospital visits in order to care for her children. In our patient, who weighed $67 \mathrm{~kg}$, the original pegfilgrastim dose of $3.6 \mathrm{mg}$ was not considered excessive $(19,20,34)$. A phase I/II study demonstrated the safety and efficacy of 
$30 \mu \mathrm{g} / \mathrm{kg}$ and $1.8 \mathrm{mg}$ of pegfilgrastim treatment in Japan. The appropriate pegfilgrastim dose for Japanese patients with breast cancer was evaluated in a previous study comparing doses of 1.8, 3.6 and $6.0 \mathrm{mg}$ (19). The primary end-point of that study was the duration of severe (grade 4) neutropenia in the first chemotherapy cycle, which correlated with the incidence of FN. Masuda et al (19) demonstrated a dose-response relationship between pegfilgrastim dose and primary end-point; a significant linear reduction was observed with a significant plateau at $3.6 \mathrm{mg}$ and non-significant reduction at $6.0 \mathrm{mg}$. However, no statistically significant differences were observed between the three arms regarding the frequency of adverse hematological events or duration of severe neutropenia. Thus, the dose reduction to $1.8 \mathrm{mg}$ in our study preserved the patient's neutrophil count.

Although there was no apparent dose-dependent induction of adverse events, the biological half-life of pegfilgrastim was not affected by the dose; therefore, pegfilgrastim dose in our patient should have been switched from 3.6 to $1.8 \mathrm{mg}$ before the onset of leukocytosis.

Following administration of $1.8 \mathrm{mg}$ pegfilgrastim, the patient's ANC on day 1 of the second DD-DTX cycle was $13,090 / \mathrm{mm}^{3}$. However, after the omission of prophylactic use of pegfilgrastim, the ANC was $297 / \mathrm{mm}^{3}$ on day 14 . Although this indicates that the effect of $1.8 \mathrm{mg}$ pegfilgrastim was not sustained for more than 14 days, a limitation of this study was that the nadir duration of $1.8 \mathrm{mg}$ pegfilgrastim was not measured during chemotherapy. Considering that the patient did not experience FN during the cycle after $1.8 \mathrm{mg}$ pegfilgrastim injection, the effect of administering each cycle can be expected. Indeed, an apparent ANC drop following administration of $1.8 \mathrm{mg}$ was observed; therefore, continuous use of $1.8 \mathrm{mg}$ pegfilgrastim during each cycle of chemotherapy may have improved leukocytosis.

Younger patients ( $<30$ years) respond strongly to $3.6 \mathrm{mg}$ pegfilgrastim. Adverse events associated with pegfilgrastim may however affect the continuity of chemotherapy. A $1.8-\mathrm{mg}$ dose of pegfilgrastim was considered an option for palliating fatigue and leukocytosis in this patient with high-risk breast cancer receiving DD chemotherapy, with the aim of preventing treatment interruption. For young patients $(<30$ years) with aggressive disease, such as TNBC, dose reduction should be avoided to maintain therapeutic effect. Conversely, treatment with daily administration of granulocyte colony-stimulating factor, may not be feasible for patients who cannot visit the hospital frequently.

The limitation of the present study was that $1.8 \mathrm{mg}$ pegfilgrastim was only administered on a single occasion during treatment; therefore, conclusions regarding its regular use compared with $3.6 \mathrm{mg}$ pegfilgrastim cannot be made based solely on this case report. However, we believe that the half-dose pegfilgrastim administration used in this case may help with the completion of optimal-dose chemotherapy with reduced inoculation frequency of granulocyte colony-stimulating factor in patients with fatigue and leukocytosis.

\section{Acknowledgements}

Not applicable.

\section{Funding}

No funding was received.

\section{Availability of data and materials}

All the data supporting the findings of the present study are included in this published manuscript and supplementary data.

\section{Authors' contributions}

HT, WT and FY participated in the treatment, data interpretation and manuscript preparation. TG and TO are the member of the cancer board, discussed about the strategy of $1.8 \mathrm{mg}$ dose of pegfilgrastim administration to this patient. HT wrote and edited the manuscript. All authors read and approved the final manuscript.

\section{Ethics approval and consent to participate}

All study participants provided informed consent, and the study design was approved by the Ethics Review Board of Shiga General Hospital. All experiments were performed in accordance with the principles outlined in the Declaration of Helsinki.

\section{Patient consent for publication}

Written informed consent was obtained from the patient for publication of this case report and any accompanying images.

\section{Competing interests}

The authors declare that they have no competing interests.

\section{References}

1. Mobus V, Jackisch C, Luck HJ, du Bois A, Thomssen C, Kuhn W, Nitz U, Schneeweiss A, Huober J, Harbeck N, et al: Ten-year results of intense dose-dense chemotherapy show superior survival compared with a conventional schedule in high-risk primary breast cancer: Final results of AGO phase III iddEPC trial. Ann Oncol 29: 178-185, 2018.

2. Mobus V, von Minckwitz G, Jackisch C, Luck HJ, Schneeweiss A, Tesch H, Elling D, Harbeck N, Conrad B, Fehm T, et al: German adjuvant intergroup Node-positive Study (GAIN): A phase III trial comparing two dose-dense regimens (iddEPC versus ddEC-PwX) in high-risk early breast cancer patients. Ann Oncol 28: 1803-1810, 2017.

3. Lambertini M, Ceppi M, Cognetti F, Cavazzini G, De Lurentiis M, De Placido S, Michelotti A, Bisagni G, Durando A, Valle E, et al: Dose-dense adjuvant chemotherapy in premenopausal breast cancer patients: A pooled analysis of the MIG1 and GIM2 phase III studies. Eur J Cancer 71: 34-42, 2017.

4. Foukakis T, von Minckwiz G, Bengtsson NO, Brandberg Y, Wallberg B, Fornander T, Mineritsch B, Schmatloch S, Singer CF, Steger G, et al: Effect of tailored dose-dense chemotherapy vs standard 3-weekly adjuvant chemotherapy on recurrence-free survival among women with high-risk early breast cancer: A Randomized Clinical Trial. JAMA 316: 1888-1896, 2016.

5. Del Mastro L, De Placido S, Bruzi P, De Laurentiis M, Boni C, Cavazzini G, Durando A, Turletti A, Nisticò C, Valle E, et al: Fluorouracil and dose-dense chemotherapy in adjuvant treatment of patients with early-stage breast cancer: An open-label, 2 × 2 factorial, randomised phase 3 trial. Lancet 385: 1863-1872, 2015. 
6. Aapro M, Boccia R, Leonard R, Camps C, Campone M, Choquet S, Danova M, Glaspy J, Hus I, Link H, et al: Refining the role of pegfilgrastim (a long-acting G-CSF) for prevention of chemotherapy-induced febrile neutropenia: Consensus guidance recommendations. Support Care Cancer 25: 3295-3304, 2017.

7. Vehreschild JJ, Bohme A, Cornely OA, Kahl C, Karthaus M, Kreuzer KA, Maschmeyer G, Mousset S, Ossendorf V, Penack O, et al: Prophylaxis of infectious complications with colony-stimulating factors in adult cancer patients undergoing chemotherapy-evidence-based guidelines from the infectious diseases working party AGIHO of the German society for haematology and medical oncology (DGHO). Ann Oncol 25: 1709-1718, 2014.

8. Smith TJ, Bohlke K, Lyman GH, Carson KR, Crawford J, Cross SJ, Goldberg JM, Khatcheressian JL, Leighl NB, Perkins CL, Somlo G, et al: Recommendations for the Use of WBC Growth Factors: American Society of Clinical Oncology Clinical Practice Guideline Update. J Clin Oncol 33: 3199-212, 2015.

9. Aapro MS, Bohlius J, Cameron DA, Dal Lago L, Donnelly JP, Kearney N, Lyman GH, Pettengell R, Tjan-Heijnen VC, Walewski J, Weber DC, et al: 2010 update of EORTC guidelines for the use of granulocyte-colony stimulating factor to reduce the incidence of chemotherapy-induced febrile neutropenia in adult patients with lymphoproliferative disorders and solid tumours. Eur J Cancer 47: 8-32, 2011.

10. Crawford J, Becker PS, Armitage JO, Blayney DW, Chavez J, Curtin P, Dinner S, Fynan T, Gojo I, Griffiths EA, Hough S et al: Myeloid Growth Factors, Version 2.2017, NCCN Clinical Practice Guidelines in Oncology. J Natl Compr Canc Netw 15: 1520-1541, 2017

11. Green MD, Koelbl H, Baselga J, Galid A, Guillem V, Gascon P, Siena S, Lalisang RI, Samonigg H, Clemens MR, et al: A randomized double-blind multicenter phase III study of fixed-dose single-administration pegfilgrastim versus daily filgrastim in patients receiving myelosuppressive chemotherapy. Ann Oncols 14: 29-35, 2003

12. Grigg A, Solal-Celigny P, Hoskin P, Taylor K, McMillan A, Forstpointner R, Bacon P, Renwick J and Hiddemann W; International Study Group: Open-label, randomized study of pegfilgrastim vs. daily filgrastim as an adjunct to chemotherapy in elderly patients with non-Hodgkin's lymphoma. Leuk Lymphoma 44: 1503-1508, 2003.

13. Holmes FA, Jones SE, O'Shaughnessy J, Vukelja S, George T, Savin M, Richards D, Glaspy J, Meza L, Cohen G, et al Comparable efficacy and safety profiles of once-per-cycle pegfilgrastim and daily injection filgrastim in chemotherapy-induced neutropenia: A multicenter dose-finding study in women with breast cancer. Ann Oncol 13: 903-909, 2002.

14. Holmes FA, O'Shaughnessy JA, Vukelja S, Jones SE, Shogan J, Savin M, Glaspy J, Moore M, Meza L, Wiznitzer I, et al: Blinded, randomized, multicenter study to evaluate single administration pegfilgrastim once per cycle versus daily filgrastim as an adjunct to chemotherapy in patients with high-risk stage II or stage III/IV breast cancer. J Clin Oncol 20: 727-731, 2002.

15. Vose JM, Crump M, Lazarus H, Emmanouilides C, Schenkein D, Moore J, Moore J, Frankel S, Flinn I, Lovelace W, et al: Randomized, multicenter, open-label study of pegfilgrastim compared with daily filgrastim after chemotherapy for lymphoma. J Clin Oncol 21: 514-519, 2003.

16. Zhang W, Jiang Z, Wang L, Li C and Xia J: An open-label, randomized, multicenter dose-finding study of once-per-cycle pegfilgrastim versus daily filgrastim in Chinese breast cancer patients receiving TAC chemotherapy. Med Oncol 32: 147, 2015.

17. Cooper KL, Madan J, Whyte S, Stevenson MD and Akehurst RL: Granulocyte colony-stimulating factors for febrile neutropenia prophylaxis following chemotherapy: Systematic review and meta-analysis. BMC Cancer 11: 404, 2011.

18. Pinto L, Liu Z, Doan Q, Bernal M, Dubois R and Lyman G: Comparison of pegfilgrastim with filgrastim on febrile neutropenia, grade IV neutropenia and bone pain: A meta-analysis of randomized controlled trials. Curr Med Res Opin 23: 2283-2295, 2007.

19. Masuda N, Tokuda Y, Nakamura S, Shimazaki R, Ito Y and Tamura K: Dose response of pegfilgrastim in Japanese breast cancer patients receiving six cycles of docetaxel, doxorubicin, and cyclophosphamide therapy: A randomized controlled trial. Support Care Cancer 23: 2891-2898, 2015.
20. Kosaka Y, Rai Y, Masuda N, Takano T, Saeki T, Nakamura S, Shimazaki R, Ito Y, Tokuda Y and Tamura K: Phase III placebo-controlled, double-blind, randomized trial of pegfilgrastim to reduce the risk of febrile neutropenia in breast cancer patients receiving docetaxel/cyclophosphamide chemotherapy. Support Care Cancer 23: 1137-1143, 2015.

21. Pawloski PA, Larsen M, Thoresen A and Giordana MD: Pegfilgrastim use and bone pain: A cohort study of community-based cancer patients. J Oncol Pharm Pract 22: 423-429, 2016.

22. Moukharskaya J, Abrams DM, Ashikaga T, Khan F, Schwartz J, Wilson K, Verschraegen C, Openshaw T, Valentine J, Eneman J, et al: Randomized phase II study of loratadine for the prevention of bone pain caused by pegfilgrastim. Support Care Cancer 24: 3085-3093, 2016.

23. Union for International Cancer Control-TNM classification, 8th edition. https://www.uicc.org/. Accessed July 17, 2019.

24. Untch M, Jackisch C, Schneeweiss A, Conrad B, Aktas B, Denkert C, Eidtmann H, Wiebringhaus $\mathrm{H}$, Kümmel $\mathrm{S}$, Hilfrich J, et al: Nab-paclitaxel versus solvent-based paclitaxel in neoadjuvant chemotherapy for early breast cancer (GeparSepto-GBG 69): A randomised, phase 3 trial. Lancet Oncol 17: 345-356, 2016.

25. ShimadaH,UedaS,SaekiT,ShigekawaT,TakeuchiH,HirokawaE, Sugitani I, Sugiyama M, Takahashi T, Matsuura K, et al: Neoadjuvant triweekly nanoparticle albumin-bound paclitaxel followed by epirubicin and cyclophosphamide for Stage II/III HER2-negative breast cancer: Evaluation of efficacy and safety. Jpn J Clin Oncol 45: 642-649, 2015.

26. Saito M, Aogi K, Sekine I, Yoshizawa H, Yanagita Y, Sakai H, Inoue K, Kitagawa C, Ogura T and Mitsuhashi S: Palonosetron plus dexamethasone versus granisetron plus dexamethasone for prevention of nausea and vomiting during chemotherapy: A double-blind, double-dummy, randomised, comparative phase III trial. Lancet Oncol 10: 115-124, 2009.

27. Tsuyuki S, Senda N, Kanng Y, Yamaguchi A, Yoshibayashi H, Kikawa Y, Katakami N, Kato H, Hashimoto T, Okuno T, et al: Evaluation of the effect of compression therapy using surgical gloves on nanoparticle albumin-bound paclitaxel-induced peripheral neuropathy: A phase II multicenter study by the Kamigata Breast Cancer Study Group. Breast Cancer Res Treat 160: 61-67, 2016.

28. Lambertini M, Del Mastro L, Bellodi A and Pronzato P: The five 'Ws' for bone pain due to the administration of granulocyte-colony stimulating factors (G-CSFs). Crit Rev Oncol Hematol 89: 112-128, 2014.

29. Hamilton JA: Colony-stimulating factors in inflammation and autoimmunity. Nat Rev Immunol 8: 533-544, 2008.

30. Stosser S, Schweizerhof M and Kuner R: Hematopoietic colony-stimulating factors: New players in tumor-nerve interactions. J Mol Med (Berl) 89: 321-329, 2011.

31. Package insert. Neulasta (pegfilgrastim). Thousand Oaks, CA, Amgen, September 15, 2005. https://www.accessdata. fda.gov/drugsatfda_docs/label/2002/pegfamg013102LB.pdf\# search $=\% 27$ Package + insert.+Neulasta $+\% 28$ pegfilgrastim $\% 29 .+$ Thousand+Oaks $\% 2 \mathrm{C}+\mathrm{CA} \% 3 \mathrm{~A}+\mathrm{Amgen} \% 2 \mathrm{C}+$ September+15\%2C+ 2005.\%27. Accessed July 17, 2019.

32. Rheingold SD and Lange BJ: Oncogenic emergencies. In: Principkes and Practice of Pediatric Oncology. 4th edition. Pizzo PA, Poplack DG, (eds). Philadelphia, Lippincott Williams \& Wilkins, pp1177-1203, 2002.

33. Schirm S, Engel C, Loibl S, Loeffler M and Scholz M: Model-based optimization of G-CSF treatment during cytotoxic chemotherapy. J Cancer Res Clin Oncol 144: 343-358, 2018.

34. Ishiguro $\mathrm{H}$, Kitano $\mathrm{T}$, Yoshibayashi, Toi M, Ueno T, Yasuda $\mathrm{H}$, Yanagihara K, Garbo CL and Fukushima M: Prolonged neutropenia after dose-dense chemotherapy with pegfilgrastim. Ann Oncol 19: 1019-1020, 2008.

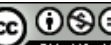

This work is licensed under a Creative Commons Attribution-NonCommercial-NoDerivatives 4.0 International (CC BY-NC-ND 4.0) License. 